Research Article

\title{
Preclinical evidence of a rapid-onset antidepressant-like effect of Pseudospondias microcarpa hydroethanolic leaf extract in a chronic depression model
}

\author{
Donatus Wewura Adongo ${ }^{1 *}$, Priscilla Kolibea Mante $^{2}$, Kennedy Kwami Edem Kukuia ${ }^{3}$, \\ Eric Woode ${ }^{2}$
}

${ }^{1}$ Department of Pharmacology, School of Medicine, University of Health and Allied Sciences, Ho, Ghana

${ }^{2}$ Department of Pharmacology, Faculty of Pharmacy and Pharmaceutical Sciences, College of Health Sciences, Kwame Nkrumah University of Science and Technology,

Kumasi, Ghana,

${ }^{3}$ Department of Pharmacology and Toxicology, University of Ghana School of Pharmacy, College of Health Sciences, University of Ghana, Accra, Ghana

Received: 25 May 2016 Accepted: 01 July 2016

*Correspondence to: Dr. Donatus Wewura Adongo, Email: donatusadongo@ yahoo.com

Copyright: (C) the author(s), publisher and licensee Medip Academy. This is an openaccess article distributed under the terms of the Creative Commons Attribution NonCommercial License, which permits unrestricted noncommercial use, distribution, and reproduction in any medium, provided the original work is properly cited.

\begin{abstract}
Background: Depression is a widespread, devastating mental illness and currently available treatments have significant limitations including low response rates and delayed onset of action. N-methyl-D-aspartate (NMDA) receptor antagonists exert fast-acting antidepressant effects. Pseudospondias microcarpa produces an antidepressant-like effect via inhibition of the glycine/NMDA receptor complex, and could therefore possess a rapid onset of action. Therefore, the present study investigated the possible rapid-onset antidepressant action of $P$. microcarpa in mice.

Methods: In this study, rapid-onset and sustained antidepressant effects of the hydroethanolic leaf extract of P. microcarpa (PME) was investigated in the open-space swim test, a chronic model of depression. Antidepressant effect was further assessed in the tail suspension test (TST). In addition, the effect of the extract on cognitive function in the Morris water maze (MWM) test was investigated.

Results: Depressed mice showed a significant increase in immobility and decrease in distance swum. However, treatment with PME and the classical antidepressants significantly decreased immobility time and increased distance swum. Furthermore, unlike the classical antidepressants which required 10-14 days to significantly improve mobility behaviour, PME treatment significantly decreased immobility time $(\mathrm{P}<0.001)$ on the first day of treatment (day 5 of stress procedure). This effect was also sustained for the remainder of the experiment. The extract also significantly decreased immobility time in the TST $(\mathrm{F} 3,16=4.881, \quad \mathrm{P}=0.0135)$ and decreased escape latency $(\mathrm{F} 4,24=12.07$, $\mathrm{P}<0.0001)$ in the MWM procedure.

Conclusions: The leaves of $P$. microcarpa exhibits rapid and sustained antidepressant effects and improve cognitive function in depressed mice.
\end{abstract}

Keywords: Pseudospondias microcarpa, Depression, Open-space swim, NMDA, MWM, Tail suspension test 


\section{INTRODUCTION}

Depression is one of the most devastating mental illnesses which results in enormous personal suffering and economic loss, with a lifetime prevalence of about $17 \% .^{1,2}$

Although in the last few decades agents that modulate the monoaminergic system are used in treating depression, their efficacies are unsatisfactory and they produce multiple unwanted side effects. ${ }^{3,4}$ Furthermore, they require several weeks to achieve therapeutic response. ${ }^{5}$ This treatment delay is a major limitation to current depression therapies, leading to increased morbidity, suicidal ideation, and loss of quality of life. ${ }^{6-8}$ For these reasons, developing faster-acting and more effective antidepressants is important, especially for depressed patients at risk for suicide. ${ }^{9}$

During the past years, several evidences have implicated the NMDA class of glutamate receptors in the pathophysiology of major depression and the mechanism of action of antidepressant treatment. ${ }^{10}$ Extensive preclinical research indicates that both competitive and non-competitive NMDA receptor antagonists, polyamine site antagonists and inorganic inhibitors of NMDA receptor function (zinc and magnesium) possess antidepressant-like activity. ${ }^{4,11,12}$ In addition, clinical evidence also shows a rapid and sustained antidepressant activity for NMDA receptor antagonists such as ketamine. ${ }^{13}$ Similar to NMDA antagonists, research has also shown that antagonists and partial agonists at the glycine site of the NMDA receptor complex exhibit rapid antidepressant-like activity in both preclinical and clinical studies. ${ }^{9,14}$

Pseudospondias microcarpa, the African grape tree, is a plant used traditionally for managing various central nervous system (CNS) disorders. ${ }^{15}$ The hydroethanolic leaf extract (PME) of the plant showed antidepressantlike effects in acute models of depression employed in the search for new antidepressants, forced swimming test (FST) and tail suspension test (TST). ${ }^{16}$ Furthermore, we demonstrated in this study that the extract elicits its antidepressant-like effect via interaction with the 5-HT system, nitric oxide pathway and glycine/NMDA receptor complex. Since the antidepressant effect of PME acts through inhibition of the glycine/NMDA receptor, we hypothesize that it could modulate glutamatergic synapses to effect a rapid-onset antidepressant-like action.

Therefore, this study assessed the onset of antidepressant effect of the extract in the open-space swim procedure, a chronic model of depression with greater face, construct, and predictive validity than the acute behavioural measures used for screening. This depression model responds to chronic but not acute or subacute administration of a variety of antidepressants, including tricyclics, selective serotonin reuptake inhibitors and monoamine oxidase inhibitors but not anxiolytics or antipsychotics. $^{17,18}$ In addition, the effects of PME on cognitive function in the Morris water maze task was assessed in this chronic model of depression.

\section{METHODS}

\section{Plant collection and extraction}

Fresh leaves of $P$. microcarpa were collected from the campus of Kwame Nkrumah University of Science and Technology (KNUST), Kumasi $\left(6^{\circ} 40.626^{\prime} \mathrm{N}, 1^{\circ}\right.$ $34.041^{\prime} \mathrm{W}$ ) and authenticated at the Department Of Herbal Medicine, Faculty of Pharmacy And Pharmaceutical Sciences, KNUST, Kumasi, Ghana. Leaves of the plant were room-dried for seven days and pulverised into fine powder. The powder was extracted by cold percolation with $70 \%(\mathrm{v} / \mathrm{v})$ ethanol in water over a period of 72 hours and the resulting extract concentrated into a syrupy mass under reduced pressure at $60{ }^{\circ} \mathrm{C}$ in a rotary evaporator. It was further dried in a hot air oven at $50{ }^{\circ} \mathrm{C}$ for a week and kept in a refrigerator for use. The yield was $20.5 \%(\mathrm{w} / \mathrm{w})$. In this study the crude extract is subsequently referred to as PME or extract.

\section{Animals}

Male ICR mice (20-25 g) were purchased from the Noguchi Memorial Institute for Medical Research, Accra, Ghana and kept in the animal house of the Department of Pharmacology, Kwame Nkrumah University of Science and Technology, Kumasi, Ghana. They were housed in standard cages and allowed free access to food and water. Prior to testing, animals were allowed to acclimatize to laboratory conditions of temperature, humidity and light. The studies were conducted in accordance with accepted principles for laboratory animal use and care. ${ }^{19}$ Approval for this study was obtained from the faculty ethics committee.

\section{Chemicals}

Desipramine hydrochloride was purchased from SigmaAldrich Inc., St. Louis, MO, USA and fluoxetine hydrochloride $\left(\operatorname{Prozac}^{\circledR}\right)$, Eli Lilly and Company Ltd., Basingstoke, England.

\section{Repeated open-space swim model}

This test is a modification of the acute forced swim paradigm. ${ }^{17,18}$ In this procedure, mice are swum for 15 $\mathrm{min} / \mathrm{d}$ for 4 days in rat tub cages $(24 \mathrm{~cm} \times 43 \mathrm{~cm} \times 23$ $\mathrm{cm}, \mathrm{w} \times \mathrm{h} \times 1)$ filled with lukewarm water $(13 \mathrm{~cm}$ deep, 32-34 ${ }^{\circ} \mathrm{C}$ ) with these cages divided into 4 imaginary quadrants. This schedule produces a progressive reduction of active swimming along with a concomitant increase in immobility (floating) which persists unaltered for weeks after the last test. 
Drug treatments begun on the fifth day. Briefly, mice were divided into 10 groups $(n=5)$ and pre-treated with vehicle $\left(10 \mathrm{ml} \mathrm{kg}^{-1}\right.$ of $0.9 \% \mathrm{NaCl}$, i.p), PME (30, 100 and $300 \mathrm{mg} \mathrm{kg}^{-1}$, p.o.), fluoxetine (3, 10 and $30 \mathrm{mg} \mathrm{kg}^{-1}$, p.o.) or desipramine (3, 10 and $30 \mathrm{mg} \mathrm{kg}^{-1}$, i.p.) 60 minutes (p.o.) or 30 minutes (i.p.) before being placed individually into the rat tub cages. The time of onset of drug action was assessed by swimming the mice at days 5, 8, 11, 14 and 18 after i.p. or oral administration. All swims were videotaped with a digital video camera placed $80 \mathrm{~cm}$ above the tub cage. Videos were rated for immobility time (drifting with no observable movements of the limbs or tail) and distance swum (number of tank quadrants entered). No special procedures were used to dry or warm the animals as they rapidly dried themselves with no observable episodes of shivering. Active swimming is defined as those swimming motions a mouse makes to move around in the pool.

\section{Tail suspension test}

Twenty four (24) hours after the last swim, animals were assessed in the TST. Briefly, mice were individually suspended by the tail from a horizontal ring-stand bar raised $30 \mathrm{~cm}$ above the floor using adhesive tape placed 1 $\mathrm{cm}$ from the tip of tail. The mice were positioned such that the base of their tail was aligned with the horizontal plane. Test sessions lasted for 6 minutes and were videotaped. Behaviours for the last 4 of the 6-minute test period were then analysed for mobility and immobility duration.

\section{Spatial working memory (Morris water maze)}

On day 21, the effects of mice behaviour on hippocampal-dependent spatial learning and memory was evaluated with the Morris water maze task. ${ }^{20}$

The MWM equipment consisted of a tank that was 120 $\mathrm{cm}$ in diameter and $60 \mathrm{~cm}$ in height, which was filled with water to the depth of $45 \mathrm{~cm}$ and maintained at $23 \pm 1$ ${ }^{\circ} \mathrm{C}$. Black non-toxic ink was added to make the water opaque. The tank was divided into four equal quadrants (NE, SE, NW and SW) by two imaginary perpendicular lines crossing the centre of the tank. A movable black circular platform (5 $\mathrm{cm}$ in diameter) was located in the centre of SW quadrant (target quadrant) and submerged 2 $\mathrm{cm}$ below the water surface so that a mouse could easily climb and escape from water. Each session was recorded with a video camera approximately $100 \mathrm{~cm}$ above the centre of the maze. The environment was kept lightless, maintaining visual extra-maze cues and minimizing the noise disturbance.

The MWM task consisted of two sections: place navigation and spatial probe trial. In the place navigation test, animals were subjected to 4 training trials of 2 minutes per day for five consecutive days (days 21-25 of treatment). It assessed the animal's motivation and ability to swim and escape from the aversive situation of being placed into the water by associating the platform with the escape. For each trial the platform was located at the centre of SW quadrant. The mouse entered the pool facing the wall from a different starting point each time so that the direct route to the platform differed. Briefly, the location of the platform remained constant and mice were allowed to swim for $60 \mathrm{~s}$ or until they located the platform. Mice that failed to locate the platform within 60 $\mathrm{s}$ were guided manually to the platform and remained for at least $5 \mathrm{~s}$ before returning to their home cage.

Twenty four (day 26) hours after the last training trial in the escape acquisition test, mice were submitted to the probe trial in which the platform was removed. In the 60s probe trial, the time in the target quadrant (the quadrant in which the platform was located in the training sessions) was obtained as a measure for spatial memory. Performance parameters measured in the MWM included latency to the platform, quadrant dwell time and swimming speed.

\section{Data analysis}

In all experiments, a sample size of 5 animals was utilized. All data are presented as mean \pm SEM. To compare differences between groups, one-way ANOVA was performed with Newman-Keuls' test as post hoc. The time-course curves were subjected to two-way (treatment $\times$ time) repeated measures analysis of variance (ANOVA) with Bonferroni's post hoc test. GraphPad Prism for Windows 5 (GraphPad Software, San Diego, CA, USA) was used for all statistical analysis. $\mathrm{P}<0.05$ (Newman-Keuls' test or Bonferroni's test) was considered statistically significant. Doses for $50 \%$ of the maximal effect $\left(\mathrm{ED}^{50}\right)$ for each drug were determined by using an iterative computer least squares method, with the following nonlinear regression (three-parameter logistic) equation.

$$
Y=\frac{a+(b-a)}{\left(1+10^{\left({\left.\log E D_{50}-X\right)}\right)}\right.}
$$

Where, $\mathrm{X}$ is the logarithm of dose and $\mathrm{Y}$ is the response. $\mathrm{Y}$ starts at a (the bottom) and goes to $\mathrm{b}$ (the top) with a sigmoid shape.

\section{RESULTS}

\section{Effect in the open-space swim test}

Mice showed a gradual and significant reduction in the distance moved as well as an increase in immobility over trials as they swum in the rat tub cages 15 minutes/day for four consecutive days. Unlike the behaviour patterns observed in the classical forced swimming test, no climbing on the wall was observed. As the trials progressed, the control mice showed a significant decrease in swimming. A maximal reduction in their mobility was reached at the $3^{\text {rd }}$ trial in these control mice. At this point, 
control mice did not make any movements other than those just sufficient to keep their heads above the water surface (immobility), a characteristic behaviour that is taken as an indicator of depression in the forced swimming test.

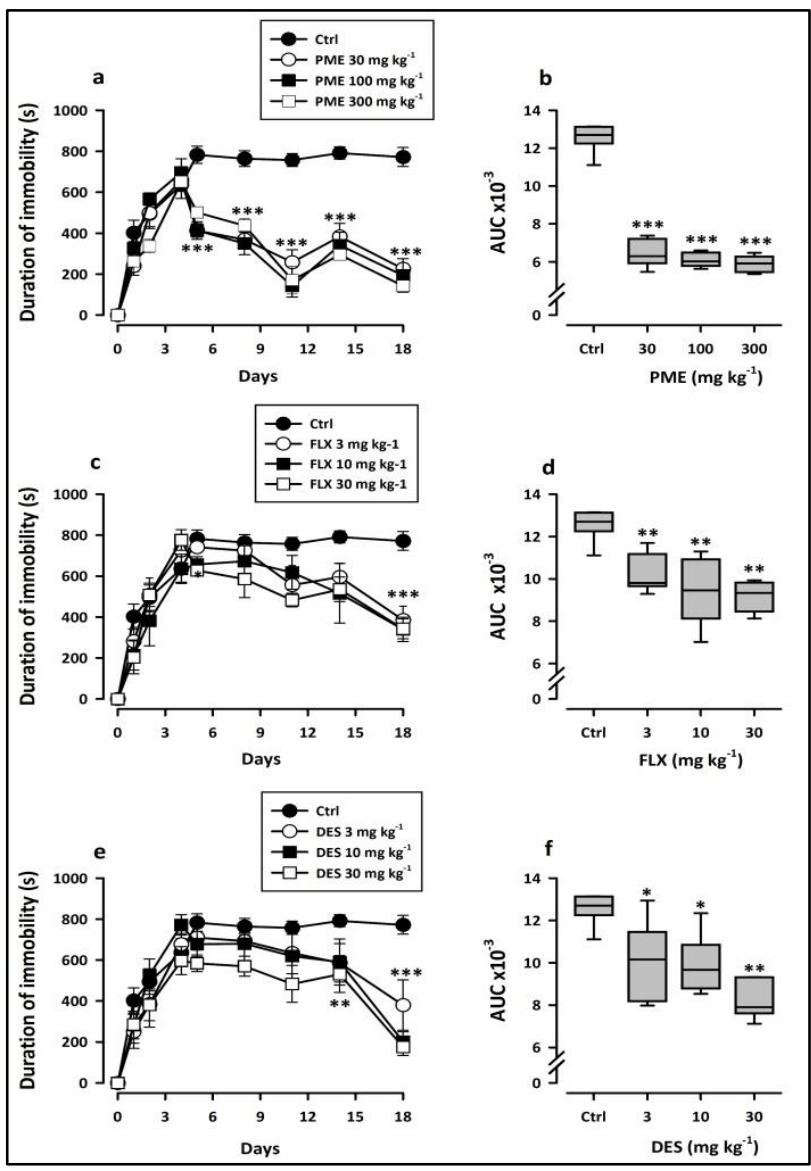

Figure 1: Effect of PME (30-300 $\left.\mathrm{mg} \mathrm{kg}^{-1}\right)$, fluoxetine, FLX (3-30 mg kg-1) and desipramine, DES (3-30 mg $\left.\mathrm{kg}^{-1}\right)$ treatment on the total duration of immobility in the open space swim test. Data are presented as both time course curves (a, c and e) and mean $\pm \operatorname{SEM}(n=5)$ of their areas under the curves (AUCs) (b, $d$ and $f$ ).

The lower and upper margins of the boxes ( $b, d$ and $f$ ) represent the $25^{\text {th }}$ and $75^{\text {th }}$ percentiles, with the extended arms representing the $10^{\text {th }}$ and $90^{\text {th }}$ percentiles, respectively. The median is shown as the horizontal line within the box and symbols represent outliers. Significantly different from control: $* \mathbf{P}<\mathbf{0 . 0 5}$, $* * \mathbf{P}<0.01, * * * \mathbf{P}<0.001$ One-way ANOVA followed by

Newman-Keuls' test for the AUCs or Two-way ANOVA followed by Bonferroni's post hoc test for time-course curves.

From the time course curves in Figure 1, without antidepressant drug (depressed group with vehicle injection), the open space swim test induced a significant increase in immobility for almost the entire duration of the experiment. However, treatment with PME and the classical antidepressants significantly increased the reduction in immobility time over the entire duration of the experiment when compared with the vehicle-treated stressed group [PME: $\mathrm{F}_{3,128}=89.81 ; \mathrm{P}<0.0001$ (Figure 1a); fluoxetine: $\quad \mathrm{F}_{3,128}=9.732, \quad \mathrm{P}=0.0007 \quad$ (Figure 1c); desipramine: $\mathrm{F}_{3,128}=8.139, \mathrm{P}=0.0016$ (Figure 1e); two-way ANOVA (treatment $\mathrm{x}$ time)]. Importantly, Bonferroni's post hoc analysis revealed a significant anti-immobility effect of PME on day 5 (treatment day 1) $(\mathrm{P}<0.001)$. In contrast, treatment with the classical antidepressants (fluoxetine and desipramine), which started 24 hours after the four open-space swim test trials, was not immediately effective. The first week of treatment did not significantly improve mobility of the mice $(\mathrm{P}>0.05$, when compared with the stressed group). The improvement was observed on day 10 of continued antidepressant treatment $(\mathrm{P}<0.05)$ and achieved its peak 2 weeks after the continued treatment $(\mathrm{P}<0.001)$.

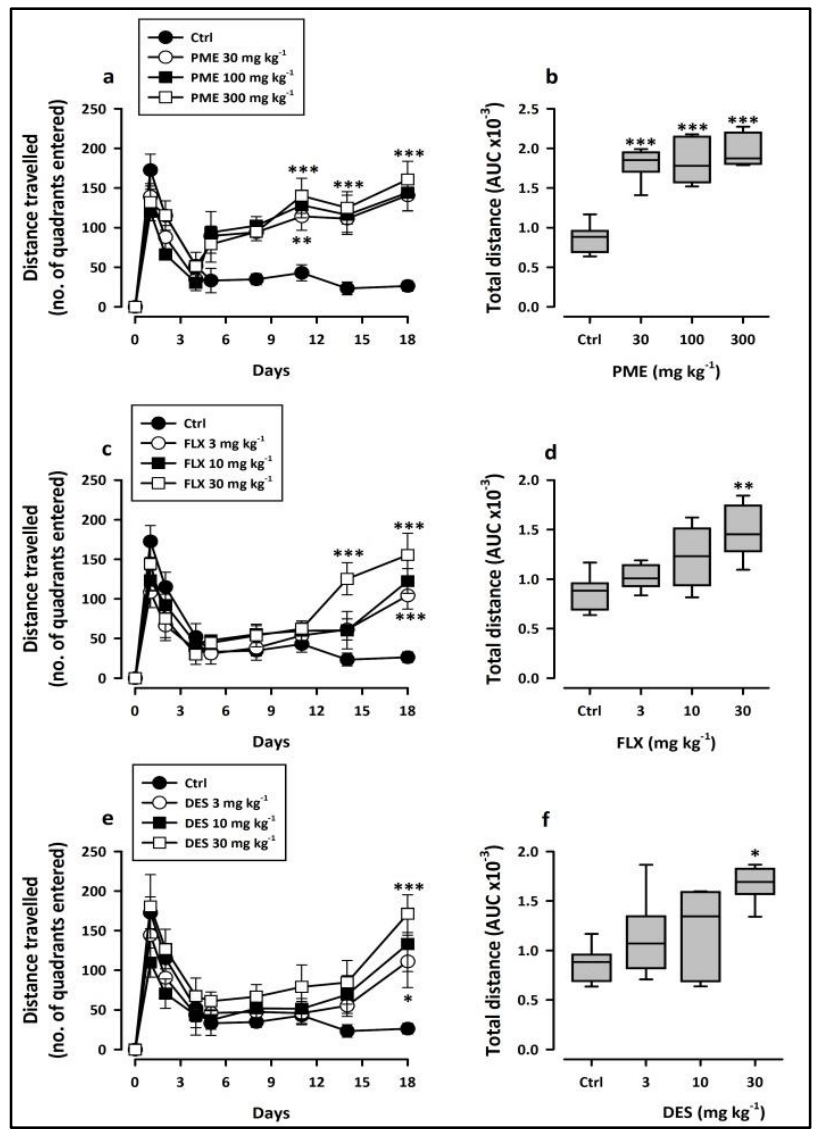

Figure 2: Effect of PME (30-300 mg kg-1), fluoxetine, FLX (3-30 mg kg-1) and desipramine, DES (3-30 mg $\mathrm{kg}^{-1}$ ) treatment on the distance travelled in the openspace swim test. Data are presented as both time course curves (a, $c$ and $e)$ and mean $\pm \operatorname{SEM}(n=5)$ of their areas under the curves (AUCs) (b, $d$ and $f$ ). The lower and upper margins of the boxes (b, $d$ and $f$ ) represent the $25^{\text {th }}$ and $75^{\text {th }}$ percentiles, with the

extended arms representing the $10^{\text {th }}$ and $90^{\text {th }}$ percentiles, respectively. The median is shown as the horizontal line within the box. Significantly different from control: $* \mathbf{P}<\mathbf{0 . 0 5}, * * \mathbf{P}<\mathbf{0 . 0 1}, * * * \mathbf{P}<\mathbf{0 . 0 0 1}$ Oneway ANOVA followed by Newman-Keuls' post hoc test for the AUCs or two-way ANOVA followed by Bonferroni's post hoc test for time-course curves. 
From the time course curves in Figure 2, all drug-treated groups displayed significant increase in the distance moved over trials when compared with the vehicle-control stressed group [PME: $\mathrm{F}_{3,128}=12.94, \mathrm{P}=0.0002$ (Figure 2b); fluoxetine: $\quad \mathrm{F}_{3,128}=3.752, \quad \mathrm{P}=0.0325 \quad$ (Figure 2d); desipramine: $\mathrm{F}_{3,128}=3.970, \mathrm{P}=0.0272$ (Figure 2f); two-way ANOVA (treatment $\mathrm{x}$ time)].

From the AUC's of the time course curves, oral administration of PME (30-300 mg kg $\mathrm{mg}^{-1}$ significantly decreased the immobility time $\left(\mathrm{F}_{3,16}=119.8, \mathrm{P}<0.0001\right.$; (Figure 1b) and increased the total distance swum $\left(F_{3,16}=22.29, \mathrm{P}<0.0001\right.$; figure $\left.2 \mathrm{~b}\right)$. Similar effects were also observed for fluoxetine [immobility: $F_{3,16}=8.946$, $\mathrm{P}=0.001 \quad$ (Figure 1d); distance swum: $\mathrm{F}_{3,16}=5.671$, $\mathrm{P}=0.0077$ (Figure 2d)] and desipramine [immobility: $\mathrm{F}_{3,16}=7.562, \quad \mathrm{P}=0.0023$ (Figure 1f); distance swum: $\mathrm{F}_{3,16}=4.554, \mathrm{P}=0.0172$ (Figure $2 \mathrm{f}$ )].
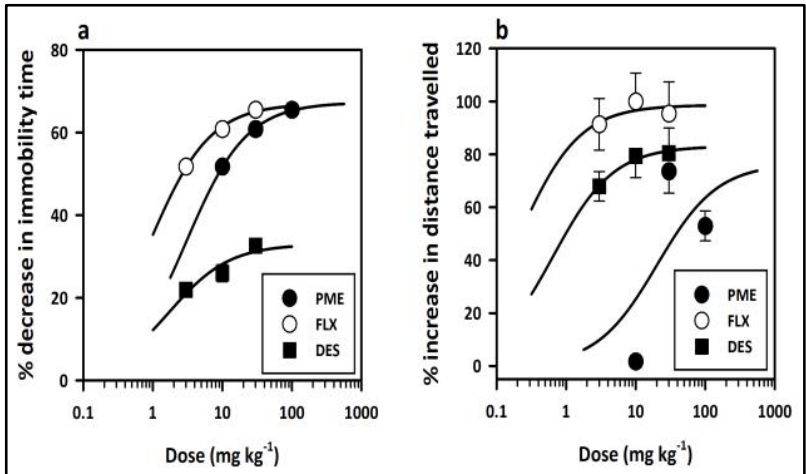

Figure 3: Dose response curves for PME (30-300 mg $\mathrm{kg}^{-1}$, p.o.), fluoxetine, FLX (3-30 $\mathrm{mg} \mathrm{kg}^{-1}$, p.o.) and desipramine, DES (3-30 $\mathrm{mg} \mathrm{kg}^{-1}$, i.p.) with respect to $\%$ decrease in immobility time (a) and \% increase in swimming time (b) in the open space swim test in mice. Each point represents the mean $\pm \operatorname{SEM}(n=5)$.

In Figure 3, PME showed more efficacy than desipramine and fluoxetine though less potent in decreasing the immobility time. The extract was however the most potent of the test compounds with regards to increase in distance travelled [PME $\left(\mathrm{ED}_{50}=5.84 \mathrm{mg} \mathrm{kg}{ }^{-1}\right) ; \mathrm{FLX}\left(\mathrm{ED}_{50}=15.29\right.$ $\left.\mathrm{mg} \mathrm{kg}{ }^{-1}\right)$; DES $\left(\mathrm{ED}_{50}=15.57 \mathrm{mg} \mathrm{kg}^{-1}\right)$.

\section{Effect in the TST}

The effects on mice behaviours in the TST 24 hours after behavioural assessment in the repeated open-space swim procedure are shown in Figure 4. One-way ANOVA revealed a significant reduction in the immobility effect of all drug-treated groups when compared to control [PME: $\mathrm{F}_{3,16}=4.881, \mathrm{P}=0.0135$; fluoxetine: $\mathrm{F}_{3,16}=4.391, \mathrm{P}=0.0195$; desipramine: $\left.\mathrm{F}_{3,16}=8.358, \mathrm{P}=0.0014\right]$.

\section{Effect of extract on spatial learning and memory}

A day after the behavioural assessment in the TST, the effects of induced depressive behaviour was tested on spatial learning in mice, using the Morris water maze (MWM). All groups showed no significant changes in escape latency during the first day as compared to the depressed control group $(\mathrm{P}>0.05)$. However, the depressive behaviour-induced increase in escape latency was eliminated by the administration of PME, fluoxetine and desipramine.

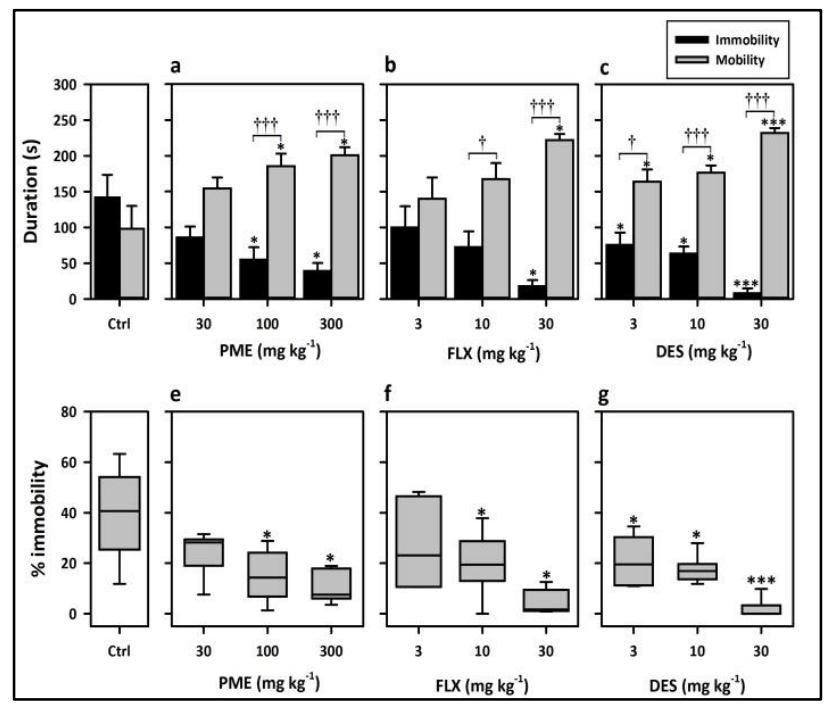

Figure 4: Effects of PME (30-300 mg kg-1), fluoxetine, FLX (3-30 mg kg-1) and desipramine, DES (3-30 mg $\mathrm{kg}^{-1}$ ) treatment on immobility and mobility duration (a, b and c) and \% immobility (e, f and $g$ ) in the TST performed after the repeated open-space swim procedure. Significantly different from control: $* \mathbf{P}<0.05, * * * \mathbf{P}<0.001$ (One-way ANOVA followed by Newman-Keuls' test) and significant difference when immobility and mobility were compared: $\uparrow \mathbf{P}<\mathbf{0 . 0 5}$, $\dagger \dagger+\mathrm{P}<0.001$ (two-way repeated measures ANOVA followed by Bonferroni's post hoc test). Data are presented as group mean \pm SEM $(n=5)$.

The change in latency to escape to the platform in all drug treated groups of mice decreased significantly following the training sessions, indicating that all mice showed some degrees of learning [PME: $\mathrm{F}_{4,100}=12.86, \mathrm{P}<0.0001$ (Figure 5a); fluoxetine: $\mathrm{F}_{4,100}=9.572, \quad \mathrm{P}<0.0002$ (Figure 5c); desipramine: $\mathrm{F}_{4,100}=16.46, \mathrm{P}<0.0001$ (Figure 5e); two-way ANOVA (treatment $x$ time)]. One-way ANOVA revealed a significant decrease in the change in escape latency for PME $\quad\left(\mathrm{F}_{4,24}=12.07, \quad \mathrm{P}<0.0001\right.$; Figure 5b), fluoxetine $\left(\mathrm{F}_{4,24}=7.555\right.$, $\mathrm{P}=0.0007$; Figure $\left.5 \mathrm{~d}\right)$ and desipramine $\left(\mathrm{F}_{4,24}=10.93\right.$, $\mathrm{P}<0.0001$; Figure 5f) when compared with depressed mice. Moreover, a post hoc analysis revealed significant differences from the third trial for all treated groups $(\mathrm{P}<0.001)$. Although a decreased change in escape latency was observed for naive group when compared to the depressed mice, this was not statistically significant. In the place navigation test, swimming speed of mice treated with the extract, fluoxetine and desipramine were not significantly affected when compared with the depressed and naïve controls (Figure 7). 


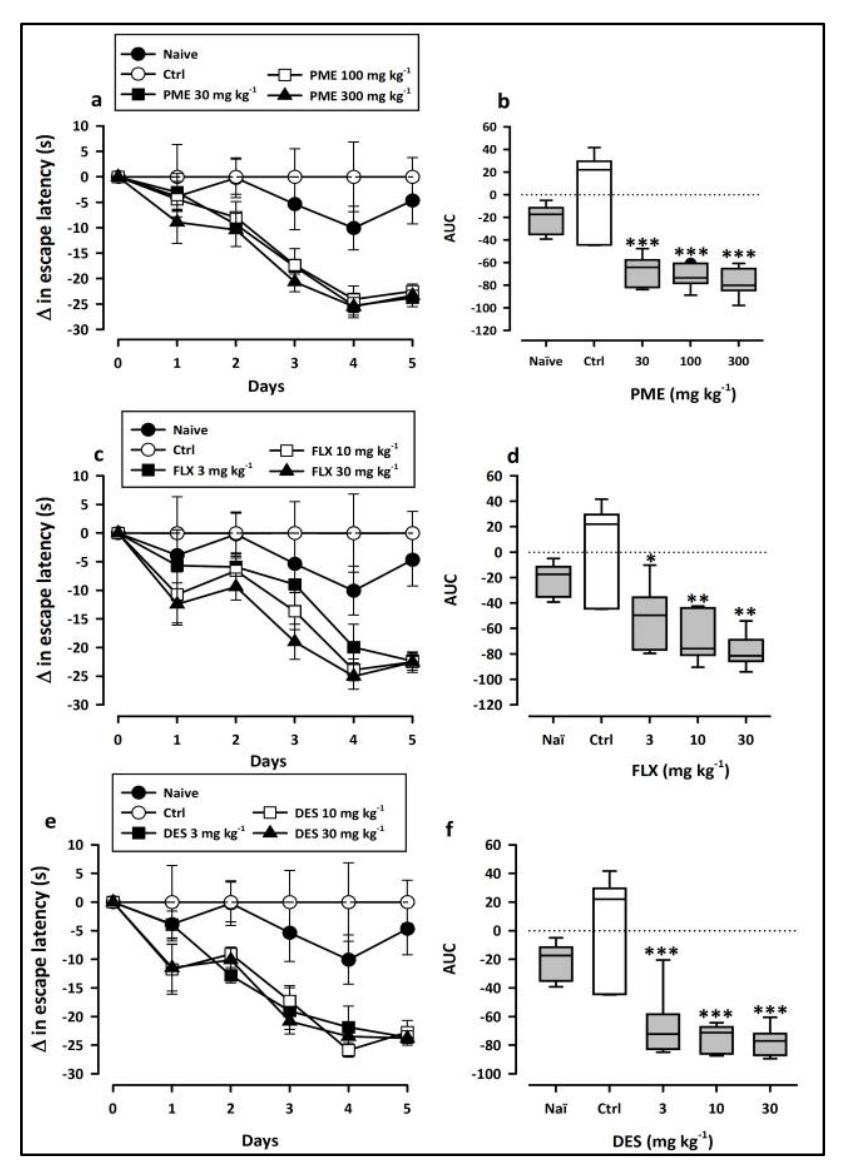

Figure 5: Effects of PME (30-300 mg kg-1), fluoxetine, FLX (3-30 $\mathrm{mg} \mathrm{kg}^{-1}$ ) and desipramine, DES (3-30 mg $\left.\mathrm{kg}^{-1}\right)$ treatments on escape latency from the place navigation session in the Morris water maze test. Data are presented as both time course curves (a, c and e) and mean $\pm \operatorname{SEM}(n=5)$ of their areas under the curves (AUCs) (b, $d$ and $f$ ). The lower and upper margins of the boxes (b, $d$ and $f$ ) represent the $25^{\text {th }}$ and $75^{\text {th }}$ percentiles, with the extended arms representing the $10^{\text {th }}$ and $90^{\text {th }}$ percentiles, respectively. The median is shown as the horizontal line within the box. Significantly different from control: $* \mathbf{P}<\mathbf{0 . 0 5}$, $* * \mathbf{P}<0.01, * * * \mathbf{P}<0.001$ (One-way ANOVA followed by Newman-Keuls' post hoc test).

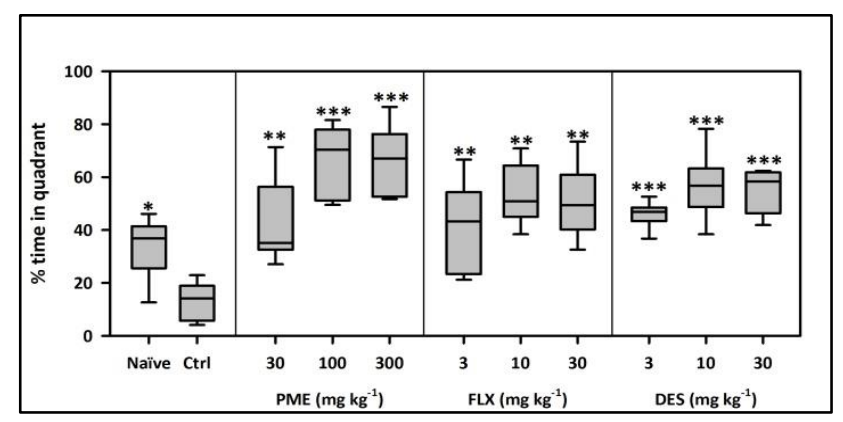

Figure 6: Effect of PME (30-300 mg kg-1), fluoxetine, FLX (3-30 $\left.\mathrm{mg} \mathrm{kg}^{-1}\right)$ and desipramine, DES (3-30 mg $\mathrm{kg}^{-1}$ ) treatments on \% time in quadrant from the probe trial session in the Morris water maze test. Data are presented as group mean $\pm \operatorname{SEM}(n=5)$. The lower and upper margins of the boxes represent the $25^{\text {th }}$ and $75^{\text {th }}$ percentiles, with the extended arms representing the $10^{\text {th }}$ and $90^{\text {th }}$ percentiles, respectively. The median

is shown as the horizontal line within the box.

Significantly different from control: $* \mathbf{P}<0.05$, $* * \mathbf{P}<0.01, * * * \mathbf{P}<0.001$ (One-way ANOVA followed by Newman-Keuls' post hoc test).

Memory retention was evaluated after the training trials. Spatial probe trial tests 24 hours after the last training trial revealed that the mice after the depressive behaviour induction did not show significant preference for the target quadrant (quadrant 4), where the platform was previously placed during the training trials. In Figure 6, administration of PME $\left(\mathrm{F}_{4,24}=13.33, \mathrm{P}<0.0001\right.$, fluoxetine $\left(\mathrm{F}_{4,24}=6.885, \mathrm{P}=0.0012\right)$ and desipramine $\left(\mathrm{F}_{4,24}=14.81\right.$, $\mathrm{P}<0.0001)$ significantly increased the percentage time spent in the target quadrant. Newman-Keuls' post hoc analysis also showed that naïve mice significantly increased percentage time spent in the target quadrant as compared to depressed mice $(\mathrm{P}<0.05)$.

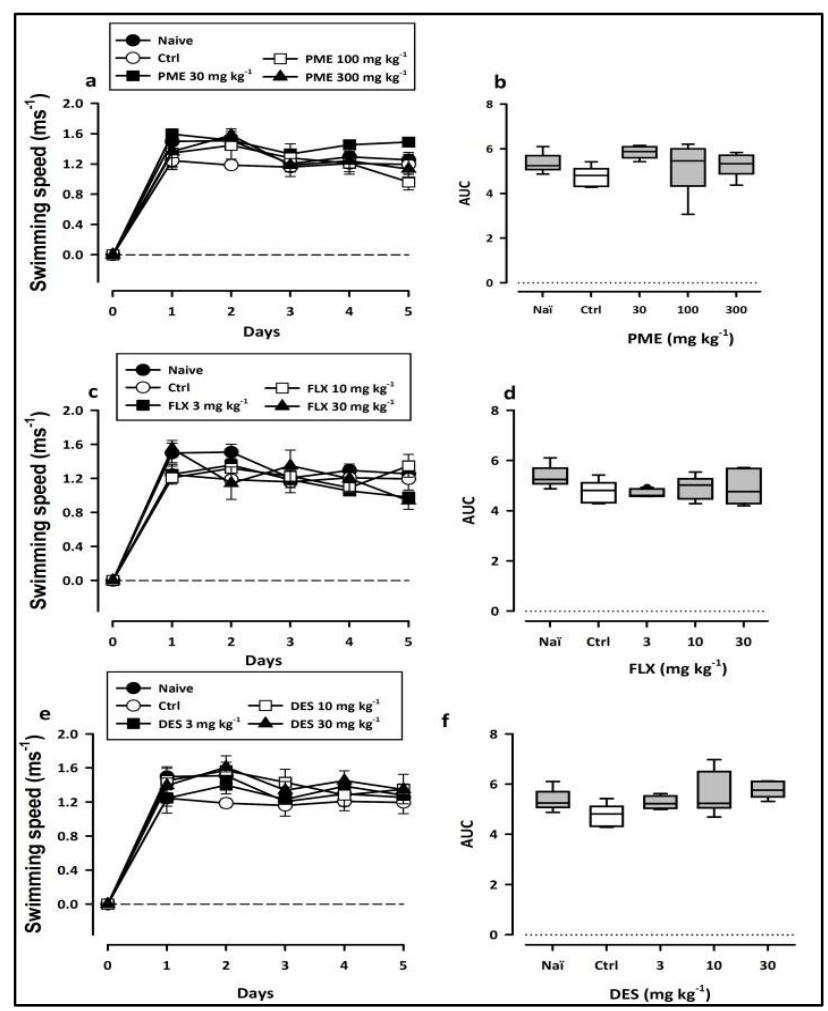

Figure 7: Effects of PME (30-300 mg kg-1), fluoxetine, FLX (3-30 mg kg-1) and desipramine, DES (3-30 mg kg-1) treatments on swimming speed from the place navigation session in the Morris water maze test. Data are presented as both time course curves ( $a, c$ and e) and mean $\pm \operatorname{SEM}(n=5)$ of their areas under the curves (AUCs) (b, $d$ and $f$ ). The lower and upper margins of the boxes ( $b, d$ and $f$ ) represent the $25^{\text {th }}$ and $75^{\text {th }}$ percentiles, with the extended arms representing the $10^{\text {th }}$ and $90^{\text {th }}$ percentiles, respectively. The median is shown as the horizontal line within the box. 


\section{DISCUSSION}

The present study provides evidence that the leaves of Pseudospondias microcarpa reverse the depressive-like behaviour induced in the repeated open-space swim test and improves cognitive function. In addition, it possesses a rapid and sustained antidepressant-like effect.

In this study, mice showed a progressive decrease of active swimming and a corresponding increase in floating behaviour that persisted for weeks with occasional repeated open-space swims. This increased inactivity was selectively reversed by the extract and the classical antidepressant drugs (desipramine and fluoxetine), in that they increased swimming behaviour as well as total distance travelled indicating antidepressant-like effects. Further evidence for a depressing effect of repeated openspace swimming was observed in the tail suspension test. Mice subjected to repeated swims were found to show increased immobility behaviour in the tail suspension test. This immobility is known to be characteristic of rodent models of depression. ${ }^{21}$ However, this effect was significantly reversed by treatment with the extract and classical antidepressants, fluoxetine and desipramine, further indicating antidepressant-like effects.

It has been demonstrated in previous experiments that the reversal of immobility and inactivity in this mouse model of depression requires about 2 weeks of antidepressant drug administration. ${ }^{18,22}$ This is further confirmed in the present study in which 2 weeks of daily treatment with both desipramine and fluoxetine, starting 24 hours after the depressive behaviour was induced, was required to produce a significant improvement in mobility in the open space swim test. In addition, results indicate that the openspace swim test induces a depressive behaviour that is not only lasting but also resemble the time course of clinical effectiveness during antidepressant drug treatment in humans. ${ }^{17,18}$ In contrast, a single administration of the extract was found to produce an immediate and significant reduction in immobility together with an increase in distance swum which was sustained for the entire duration of the experiment. This finding indicates that PME has a rapid and sustained antidepressant-like action giving it an advantage over the classical antidepressants. Moreover, the extract was the most efficatious in reducing immobility behaviour in depressed mice.

Research has shown that NMDA receptor antagonists such as ketamine, produce a rapid (within hours) and sustained (1-2 weeks) antidepressant effect in patients with treatment-resistant depression. ${ }^{13}$ This rapid and sustained antidepressant effects has been hypothesized to be the result of synaptic potentiation and early neuroplastic changes respectively. ${ }^{23,24}$ Similar to the results obtained for ketamine, glycine site NMDA receptor antagonists or partial agonists also possess rapid and sustained antidepressant effects in animal models as well as in clinical trials. ${ }^{9,14}$ However, unlike the severe side effects induced by competitive and noncompetitive NMDA antagonists which limit their use as antidepressants, ${ }^{4}$ research has proven that glycine site NMDA receptor antagonists and partial agonists have favorable safety profile. ${ }^{25}$ This therefore makes them potential candidates for the treatment of depression. ${ }^{4}$

In a previous study, we have demonstrated in our laboratory that the antidepressant-like activity of PME acts via inhibtion of the glycine/NMDA receptor complex. ${ }^{16}$ Therefore, this rapid and sustained antidepressant effect observed for PME in the repeated open-space forced swim procedure could possibly be through its interaction with NMDA receptors. This therefore gives it an advantage over the conventional antidepressants and further suggests that modulation of the glutamatergic system may be a critical therapeutic target for obtaining rapid antidepressant actions. Moreover, since the extract acts via inhibition of the glycine site of the NMDA receptor complex, it can be suggested that its rapid-onset antidepressant effects could be devoid of side effects which limits the use of noncompetitive NMDA receptor antagonists such as ketamine as antidepressants.

Lines of evidences have suggested that impaired cognition is an element of depression and that antidepressant therapy may improve cognitive function. ${ }^{26,27}$ Thus, the effects of PME on cognitive function in the Morris water maze task was asssessed in depressed mice. The Morris water maze (MWM) task is a well-validated method for evaluating learning and memory. It can reliably express hippocampusrelated acquisition and the persistence of spatial memory. ${ }^{28,29}$ Learning is measured as a decreased latency to discover the hidden platform whereas memory is the increased time spent in the area of the platform during a test session in which the platform has been removed. ${ }^{30}$

Data from this study indicates that the depressivebehaviour induced by the repeated open-space swim test impairs hippocampal-dependent spatial learning and memory performance. This finding is in agreement with a study showing similar deficits in spatial learning and memory following repeated open-space forced swim procedure.22 The learning ability was mainly reflected by the performances in place navigation section. Results of this study revealed that with increase of training days, escape latencies were consistently decreased and there was prominent improvement during the last three days in mice treated with the extract and antidepressants. Furthermore, the persistence of spatial memory was mainly reflected through mouse performances in spatial probe trial. It was observed that quadrant dwell time was significantly decreased in depressed mice. However, treatment with the extract and the classical antidepressants ameliorated this defect efficiently indicating improved memory. These findings therefore indicate improved cognitive function of the extract in depressed mice.

Several reports have shown that the 5-HT system plays an important role in cognitive function, such as learning and memory, demonstrated through the activation or blockade 
of 5-HT receptor subtypes as well as its reuptake sites. ${ }^{31-33}$ For example, it was observed that fluoxetine and tianeptine reversed memory impairments induced by scopolamine (a cholinergic antagonist) and dizocilpine (a glutamatergic antagonists). ${ }^{26,34}$ Furthermore, although blockade of NMDA receptors leads to impairment of neuronal plasticity (learning), ${ }^{35}$ studies have also indicated cognitive enhancing effects. ${ }^{36,37}$ For instance, memantine, a noncompetitive NMDA receptor antagonist, has demonstrated cognitive and behavioural improvements in both humans, ${ }^{38}$ and animals. ${ }^{39,40}$ As indicated earlier, the extract exerts its antidepressant effects via interaction with the 5-HT system and glycine/NMDA site. Therefore, reversal of the chronic depression-induced memory deficits by PME could possibly be due to its interaction with the 5-HT system and glycine/NMDA receptor complex.

Although pretreatment with PME and the classical antidepressants improves spatial learning and memory of depressed mice in the repeated open-space procedure, it is necessary to deduce whether altered acquisition reflects impairment of learning or memory. Analysis of swimming velocity to reach the platform revealed no differences between depressed and treated animals, ruling out any nonspecific effects of induced-depressive behaviour on spatial acquisition and memory. This finding demonstrates that improvement of spatial learning and memory by PME and the classical antidepressants in depressed mice are not due to any nonspecific changes in gross motor activity or motivational state.

\section{CONCLUSION}

The present study provides preclinical evidence that the hydroethanolic leaf extract of $P$. microcarpa exerts a rapid and sustained antidepressant-like effect and improves cognitive function.

\section{ACKNOWLEDGMENTS}

Authors are grateful to Messrs Thomas Ansah, Gordon Darku, Prosper Akortia, Edmond Dery and Prince Okyere of the Department of Pharmacology for their technical assistance.

\section{Funding: No funding sources}

Conflict of interest: None declared

Ethical approval: The study was approved by the Institutional Ethics Committee

\section{REFERENCES}

1. Kessler RC, Berglund P, Demler O, Jin R, Koretz D, Merikangas KR, et al. The epidemiology of major depressive disorder: results from the national comorbidity survey replication (NCS-R). Jama. 2003;289(23):3095-105.

2. Duman RS. Pathophysiology of depression and innovative treatments: remodeling glutamatergic synaptic connections. Dialogues Clin Neurosci. 2014;16(1):11-27.

3. Dang H, Chen Y, Liu X, Wang Q, Wang L, Jia W, et al. Antidepressant effects of ginseng total saponins in the forced swimming test and chronic mild stress models of depression. Progress in NeuroPsychopharmacology and Biological Psychiatry. 2009;33(8):1417-24.

4. Poleszak E, Wlaz P, Szewczyk B, Wlaz A, Kasperek $\mathrm{R}$, Wrobel A, et al. A complex interaction between glycine/NMDA receptors and serotonergic/ noradrenergic antidepressants in the forced swim test in mice. J Neural Transm. 2011;118(11):1535-46.

5. Katz MM, Tekell JL, Bowden CL, Brannan S, Houston JP, Berman N, et al. Onset and early behavioral effects of pharmacologically different antidepressants and placebo in depression. Neuropsychopharmacology: official publication of the American College of Neuropsycho Pharmacology. 2004;29(3):566-79.

6. Alamo C, López-Muñoz F. New antidepressant drugs: beyond monoaminergic mechanisms. Current pharmaceutical design. 2009;15(14):1559-62.

7. Browne CA, Lucki I. Antidepressant effects of ketamine: mechanisms underlying fast-acting novel antidepressants. Frontiers in pharmacology. 2013;4:161.

8. Machado-Vieira R, Baumann J, Wheeler-Castillo C, Latov D, Henter ID, Salvadore G, et al. The timing of antidepressant effects: a comparison of diverse pharmacological and somatic treatments. Pharmaceuticals. 2010;3(1):19-41.

9. Zhu WL, Wang SJ, Liu MM, Shi HS, Zhang RX, Liu JF, et al. Glycine site N-methyl-D-aspartate receptor antagonist 7-CTKA produces rapid antidepressantlike effects in male rats. Journal of psychiatry and neuroscience: JPN. 2013;38(5):306-16.

10. Hashimoto K. The role of glutamate on the action of antidepressants. Prog Neuropsychopharmacol Biol Psychiatry. 2011;35(7):1558-68.

11. Szewczyk B, Poleszak E, Sowa-Kucma M, Siwek M, Dudek D, Ryszewska-Pokrasniewicz B, et al. Antidepressant activity of zinc and magnesium in view of the current hypotheses of antidepressant action. Pharmacol Rep. 2008;60(5):588-9.

12. Wlaz P, Kasperek R, Wlaz A, Szumilo M, Wrobel A, Nowak G, et al. NMDA and AMPA receptors are involved in the antidepressant-like activity of tianeptine in the forced swim test in mice. Pharmacol Rep. 2011;63(6):1526-32.

13. Zarate CA, Singh JB, Carlson PJ. A randomized trial of an n-methyl-d-aspartate antagonist in treatmentresistant major depression. Archives of General Psychiatry. 2006;63(8):856-64.

14. Shin IJ, Son SU, Park H, Kim Y, Park SH, Swanberg $\mathrm{K}$, et al. Preclinical evidence of rapid-onset antidepressant-like effect in radix polygalae extract. PloS one. 2014;9(2):e88617.

15. Burkill HM. The Useful Plants of West Tropical Africa: Royal Botanic Gardens. 1986;40(2):176-6. 
16. Adongo DW, Kukuia KKE, Mante PK, Ameyaw EO, Woode E. Antidepressant-like effect of the leaves of pseudospondias microcarpa in mice: evidence for the involvement of the serotoninergic system, NMDA receptor complex, and nitric oxide pathway. BioMed Research International. 2015;2015:15.

17. Sun MK, Alkon DL. Open space swimming test to index antidepressant activity. Journal of Neuroscience Methods. 2003;126(1):35-40.

18. Stone EA, Lin Y, Quartermain D. Evaluation of the repeated open-space swim model of depression in the mouse. Pharmacology Biochemistry and Behavior. 2008;91(1):190-5.

19. NRC. Guide for the care and use of laboratory animals. Washington (DC): National Academies Press (US); 2010. Available at https://grants.nih.gov/grants/olaw/Guide-for-theCare-and-use-of-laboratory-animals.pdf.

20. Vorhees CV, Williams MT. Morris water maze: procedures for assessing spatial and related forms of learning and memory. Nat Protocols. 2006;1(2):84858.

21. Cryan JF, Mombereau C, Vassout A. The tail suspension test as a model for assessing antidepressant activity: review of pharmacological and genetic studies in mice. Neurosci Biobehav Rev. 2005;29(4-5):571-625.

22. Sun MK, Alkon DL. Induced depressive behavior impairs learning and memory in rats. Neuroscience. 2004;129(1):129-39.

23. Machado-Vieira R, Salvadore G, Luckenbaugh DA, Manji HK, Zarate CA. Rapid onset of antidepressant action: a new paradigm in the research and treatment of major depressive disorder. The Journal of clinical psychiatry. 2008;69(6):946-58.

24. Zarate C, Machado-Vieira R, Henter I, Ibrahim L, Diazgranados N, Salvadore G. Glutamatergic modulators: the future of treating mood disorders? Harvard Review of Psychiatry. 2010;18(5):293-303.

25. Beardsley PM, Ratti E, Balster RL, Willetts J, Trist D. The selective glycine antagonist gavestinel lacks phencyclidine-like behavioral effects. Behav Pharmacol. 2002;13:583-92.

26. Meneses A. Tianeptine: 5-HT uptake sites and 5HT1-7 receptors modulate memory formation in an autoshaping pavlovian/instrumental task. Neurosci Biobehav Rev. 2002;26(3):309-19.

27. Song L, Che W, Min-wei W, Murakami Y, Matsumoto K. Impairment of the spatial learning and memory induced by learned helplessness and chronic mild stress. Pharmacology Biochemistry and Behavior. 2006;83(2):186-93.

28. Ibi D, Takuma K, Koike H, Mizoguchi H, Tsuritani $\mathrm{K}$, Kuwahara Y, et al. Social isolation rearinginduced impairment of the hippocampal neurogenesis is associated with deficits in spatial memory and emotion-related behaviors in juvenile mice. Journal of Neurochemistry. 2008;105(3):921-32.

29. Clark RE, Broadbent NJ, Squire LR. The hippocampus and spatial memory: findings with a novel modification of the water maze. The Journal of Neuroscience. 2007;27(25):6647-54.

30. Kenney J, Gould T. Modulation of hippocampusdependent learning and synaptic plasticity by nicotine. Mol Neurobiol. 2008;38(1):101-21.

31. Meneses A. Do serotonin1-7 receptors modulate short and long-term memory? Neurobiology of Learning and Memory. 2007;87(4):561-72.

32. King MV, Marsden CA, Fone KC. A role for the 5HT (1A), 5-HT4 and 5-HT6 receptors in learning and memory. Trends in pharmacological sciences. 2008;29(9):482-92.

33. Mørk A, Montezinho LP, Miller S, Trippodi-Murphy C, Plath N, Li Y, et al. Vortioxetine (Lu AA21004), a novel multimodal antidepressant, enhances memory in rats. Pharmacology Biochemistry and Behavior. 2013;105:41-50.

34. Meneses A, Hong E. Effect of fluoxetine on learning and memory involves multiple 5-HT systems. Pharmacology Biochemistry and Behavior. 1995;52(2):341-6.

35. Collingridge GL, Bliss TVP. Memories of NMDA receptors and LTP. Trends in Neurosciences. 1995; 18(2):54-6.

36. Parsons CG, Stöffler A, Danysz W. Memantine: a NMDA receptor antagonist that improves memory by restoration of homeostasis in the glutamatergic system - too little activation is bad, too much is even worse. Neuropharmacology. 2007;53(6):699-723.

37. Cole PD, Vijayanathan V, Ali NF, Wagshul ME, Tanenbaum EJ, Price J, et al. Memantine protects rats treated with intrathecal methotrexate from developing spatial memory deficits. Clinical Cancer Research. 2013;19(16):4446-54.

38. Schulz JB, Rainer M, Klünemann HH, Kurz A, Wolf S, Sternberg K, et al. Sustained effects of once-daily memantine treatment on cognition and functional communication skills in patients with moderate to severe alzheimer's disease: results of a 16-week openlabel trial. Journal of Alzheimer's Disease. 2011;25(3):463-75.

39. Minkeviciene R, Banerjee P, Tanila H. Cognitionenhancing and anxiolytic effects of memantine. Neuropharmacology. 2008;54(7):1079-85.

40. Borre Y, Bosman E, Lemstra S, Westphal KG, Olivier B, Oosting RS. Memantine partly rescues behavioral and cognitive deficits in an animal model of neurodegeneration. Neuropharmacology. 2012;62(5-6):2010-7.

Cite this article as: Adongo DW, Mante PK, Kukuia KKE, Woode E. Preclinical evidence of a rapid-onset antidepressant-like effect of Pseudospondias microcarpa hydroethanolic leaf extract in a chronic depression model. Int J Basic Clin Pharmacol 2016;5:1254-62. 